\title{
Um novo Phaneropteridae brasileiro do gênero Aegimia
}

\author{
S. DE TOLEDO PIZA
}

Professor de Zoologia, Anatomia e Fisiologia da Escola Superior de Agricultura "Luiz de Queiroz" da Universidade de S. Paulo

Aegimia catharinensis sp. $n$.

Mas. Castaneus. Caput obliquum, vertice crasso, conico, ad apicem fortiter bidentato, superne ruguloso, sparsim nigronitido granulato, prope apicem sulcato et excavato, fronte tricarinata, nigro-nitido granulata, genis modice rugulosis, nigro-nitido granulatis. Oculi magni, paulo promimentes, superne et postice angustiores. Antennae filiformes, graciles, nigro anulatae, ad basin nodulosae, articulo I magno, intus processu brevi, obtuso armato. Processus frontalis robustus, recurvus, versus apicem modice angustatus, apice triangulariter truncatus, lateribus subplanis, obliquis, sparsim nigro granulatis ,parte inferiore latissima, haud excavata sed marginibus modice prominentibus, granulis nigris nonnullis praedita. Pronôtum disco plano, antice quam postice valde angustiore, módice irregulariter ruguloso, partim cinerescenti, granulis nonnulis albis, duobus nigris symetricis ad trientem anteriorem prope sulcum, nonnullis minoribus antice et postice obtecto, margine antico regulariter recurvo, postico subrotundato, in medio vix inciso, marginibus lateralibus rotundatis, haud elevatis, indistincte crenulatis, lobis deflexis angulatim insertis, perpendicularibus, compressis, aeque longis ac altis, rugulosis, parce albo granulatis, antice et postice granulis nonnullis nigris praeditis, margine antico subrecto, obliquo, margine postico rotundato, margine inferiore sinuoso. Elytra ovalia, 


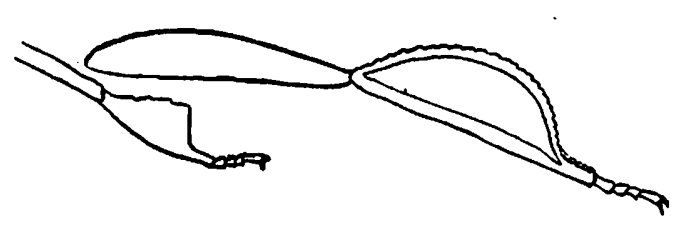

Tíbia média e pata pos-

Aegimia catharinensis sp. $n$.

partim viridia, postice quam antice magis rotundata, apice obtuso, rotundato, venis radialibus leviter flexuosis, campo praeradiali campo postradiali multo angustiore, vena ulnari anteriore a vena radiali posteriore paulo remota et cum illa a venulis transversis connecta, granulis nigris sparsis, in campo antico majoribus et magis numerosis, obtecta. Campus tympanalis disco pronoti longior, in elytro sinistro vena stridulanti crassa, humili, vix arcuata, in elytro dextro speculo triangulari prateditus. Alae hyalinae. Meso et metasterna nigro maculata. Trochanteres inferne nigro granulati. Femora antica indistincte granulata, margine inferiore antico spinis 4, necnon granulis nonnullis praedito; tibiae anticae nigro signatae; basi crassiore. Femora intermedia parcissime nigro granulata; tibiae intermediae nigro signatae, lobo latissimo ferrugineo, minutissime granulato, superne extus 3-4 dentato. Femora postica elongata, valde compressa, sparsim nigro granulata; tibiae posticae rotundatim ampliatissimae, marginibus superioribus minutissime spinulosis, inferne ad basin macula nigra rotundata ornatae. Segmenta abdominalia ventralia I et II maculis nigrin binis praedita, segmentum ultimum truncatum. Cerci conici, curvi, extremitatem versus valde attenuati. Lamina subgenilis in medio carinata, apice fortiter emarginato.

Longitudo corporis ............. $33,0 \mathrm{~mm}$

Longitudo pronoti $\ldots \ldots \ldots \ldots \ldots \ldots, 9,5 \mathrm{~mm}$

Latitudo pronoti maxima .......... $6,5 \mathrm{~mm}$

Longitudo elytrorum ............ 44,0 mm

Latitudo elytrorum maxima ....... 18,8 mm

Longitudo femorum intermediorum . $9,0 \mathrm{~mm}$

Longitudo tibiarum intermediarum .. $7,0 \mathrm{~mm}$

Longitudo lobi tibiarum intermediarum $5,0 \mathrm{~mm}$

Latitudo lobi tibiarum intermediarum $3,0 \mathrm{~mm}$

Longitudo femorum posticorum ....20,0 mm

Longitudo tibiarum posticarum .... $20,0 \mathrm{~mm}$

Latitudo tibiarum posticarum in medio $5,8 \mathrm{~mm}$

Pátria : Ribeirão do Engenho, Vale do Itauna, E. do Espírito Santo.

Col.: Travassos \& Santos, 9-X-1942.

Tipo: Um macho pertencente ao Museu Nacional, presentemente na coleção do autor. 